- Sialolthiasis is the most common disease of the salivary glands.

- Large sialoliths have rarely been reported in the salivary ducts.

- Conservative treatment may be of benefit in the treatment of sialolithiasis.

- Lithotripsy is emerging as a valuable alternative to salivary glands removal in persistent cases of sialadenitis related to sialolithiasis.

\title{
Sialolithiasis: an unusually large submandibular salivary stone
}

\author{
S. J. Siddiqui ${ }^{1}$
}

\begin{abstract}
Salivary gland calculi account for the most common disease of the salivary glands. The majority of sialoliths occur in the submandibular gland or its duct and are a common cause of acute and chronic infections. This case report describes a patient presenting with an unusually large submandibular gland sialolith, the subsequent patient management, the aetiology, diagnosis and various treatment modalities available for management of salivary gland calculi depending on their site and size.
\end{abstract}

Sialolithiasis is the most common disease of salivary glands. It is estimated that it affects 12 in 1000 of the adult population. ${ }^{1}$ Males are affected twice as much as females. ${ }^{2}$ Children are rarely affected but a review of the literature reveals 100 cases of submandibular calculi in children aged 3 weeks to 15 years old. ${ }^{3}$

Sialolithiasis accounts for more than $50 \%$ of diseases of the large salivary glands and is thus the most common cause of acute and chronic infections. ${ }^{4}$ More than $80 \%$ occur in the submandibular gland or its duct, $6 \%$ in the parotid gland and $2 \%$ in the sublingual gland or minor salivary glands. Multiple calculi in the submandibular gland are rare, ${ }^{5}$ as is simultaneous lithiasis in more than one salivary gland. ${ }^{4}$ Forty per cent of parotid and 20\% of submandibular stones are not radiopaque and sialography may be required to locate them. ${ }^{2}$ Salivary calculi are usually unilateral and are not a cause of dry mouth. ${ }^{2}$ Clinically they are round or ovoid, rough or smooth and of a yellowish colour. They consist of mainly

Senior House Officer, Maxillofacial Unit, Royal Hospital Haslar, Haslar Road, Gosport, Hants P012 2AA Correspondence to: Major S. J. Siddiqui, Defence Dental Agency HQ, RAF Halton, Aylesbury, BUCKS HP22 5PG, UK

\section{Refereed Paper}

Received 30.05.01; Accepted 05.12.01

() British Dental Journal 2002; 193: 89-91 calcium phosphate with smaller amounts of carbonates in the form of hydroxyapatite, with smaller amounts of magnesium, potassium and ammonia. This mix is distributed evenly throughout. ${ }^{6}$ Submandibular stones are $82 \%$ inorganic and 18\% organic material whereas parotid stones are composed of 49\% inorganic and 51\% organic material. ${ }^{4}$ The organic material is composed of various carbohydrates and amino acids. ${ }^{6}$ Bacterial elements have not been identified at the core of a sialolith. ${ }^{6}$

\section{CASE REPORT}

A 52-year-old lady presented at the Maxillofacial Unit, Royal Hospital Haslar following referral by her general dental practitioner (GDP) for an opinion on a firm mass in the anterior part of the right side of the floor of the mouth. The patient was unaware of the swelling and only noticed it when it was pointed out by her GDP.

Extra-oral examination revealed a palpable right submandibular gland and intraoral examination revealed a large, firm, non-tender swelling in the right anterior floor of mouth in the region of the submandibular duct. A lower occlusal radiograph showed the mass to be radiopaque and extending back beyond the lower right first permanent molar (fig. 1).

A diagnosis of right submandibular duct calculus was made and at a subsequent appointment the stone was removed under local anaesthetic with sharp dissection. It was measured to be $30 \mathrm{~mm}$ long along its greatest length (figs 2 and 3).

Due to the swelling in the right submandibular triangle and the size of the stone, the patient was reviewed two weeks post operatively to check salivary function of the gland. On review the right submandibular gland was palpable but clear saliva could be expressed from the duct on massage.

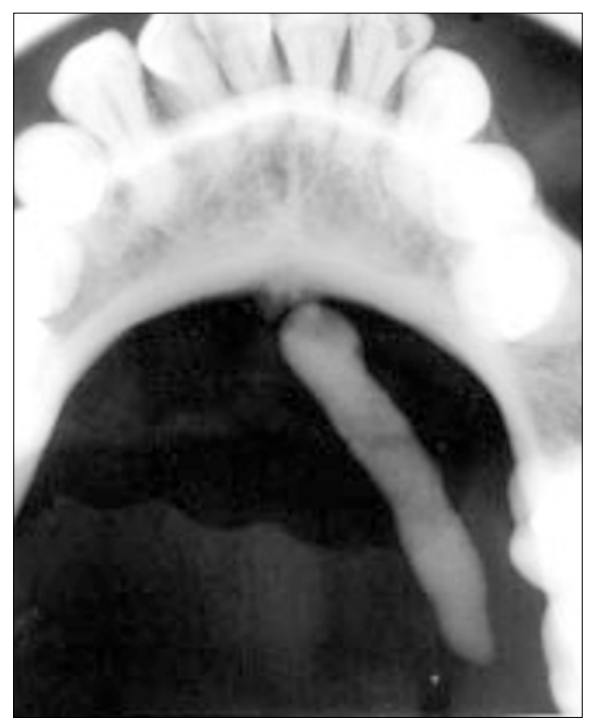

Figure 1 Lower occlusal radiograph showing submandibular salivary stone 


\section{DISCUSSION}

Although large sialoliths have been reported in the body of salivary glands, ${ }^{7-10}$ they have been rarely been reported in the salivary ducts. ${ }^{11,12-14}$ Messerly removed a $51 \mathrm{~mm}$ long calculus that occupied the entire length of Stenson's duct in a 66-year-old man. ${ }^{13}$ Brusati and Fiamminghi removed a sialolith from the left submandibular duct of a 55year-old man measuring $27 \times 31 \mathrm{~mm} .{ }^{14}$ More recently Leung et al. removed a sialolith $14 \times 9 \mathrm{~mm}$ from the right submandibular duct. ${ }^{1}$ The sialolith removed in our case was comparable to these.

\section{Aetiology}

The exact aetiology and pathogenesis of salivary calculi is largely unknown. Genesis of calculi lies in the relative stagnation of calcium rich saliva. They are thought to occur as a result of deposition of calcium salts around an initial organic nidus consisting of altered salivary mucins, bacteria and desquamated epithelial cells. ${ }^{2,15}$ For stone formation it is likely that intermittent stasis produces a change in the mucoid element of saliva, which forms a gel. This gel produces the framework for deposition of salts and organic substances creating a stone. ${ }^{6}$ Traditional theories suggest that the formation occurs in two phases: a central core and a layered periphery. ${ }^{16}$ The central core is formed by the precipitation of salts, which are bound by certain organic substances. The second phase consists of the layered deposition of organic and non organic material. ${ }^{17}$ Submandibular stones are thought to form around a nidus of mucous, ${ }^{18}$ whereas parotid stones are thought to form most often around a nidus of inflammatory cells or a foreign body. ${ }^{18,19,20}$ Another theory has proposed that an unknown metabolic phenomenon can increase the saliva bicarbonate content, which alters calcium phosphate solubility and leads to precipitation of calcium and phosphate ions. ${ }^{6,21}$ A retrograde theory for sialolithiasis has also been proposed. ${ }^{16}$ Aliments, substances or bacteria within the oral cavity might migrate into the salivary ducts and become the nidus for further calcification. A case in which a stone formation

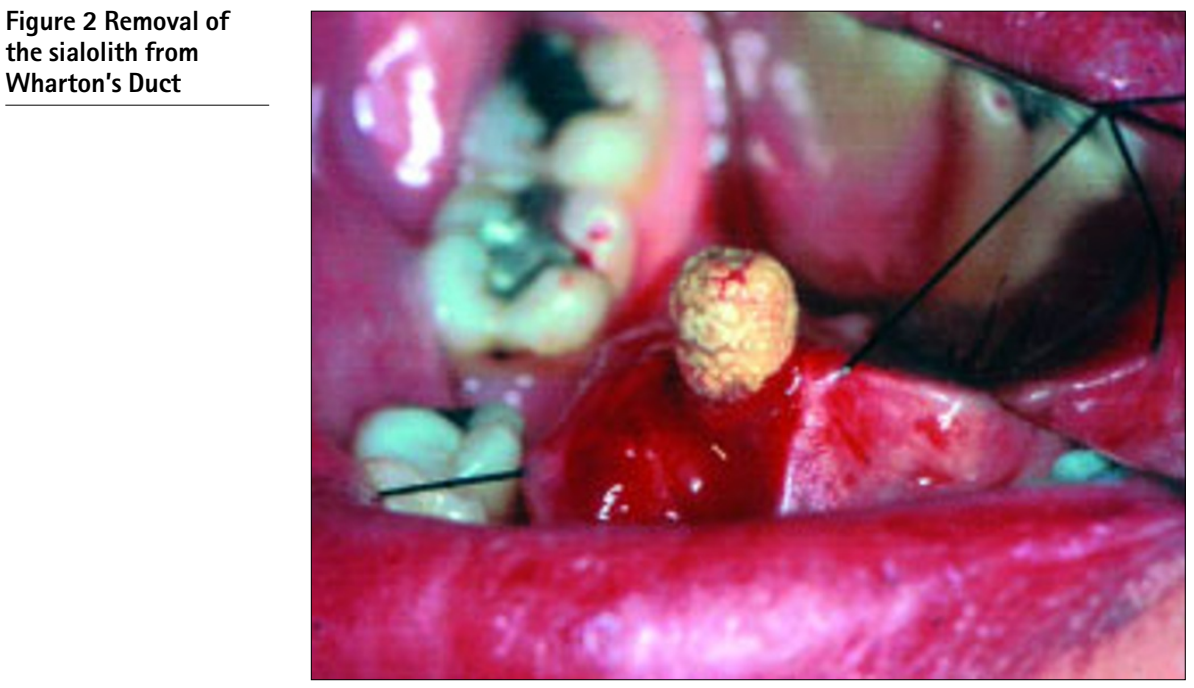

around a vegetal nidus was histologically proven has been reported. ${ }^{16}$ Salivary stagnation, increased alkalinity of saliva, infection or inflammation of the salivary duct or gland, and physical trauma to salivary duct or gland may predispose to calculus formation. ${ }^{1}$ Submandibular sialolithiasis is more common as its saliva is (i) more alkaline, (ii) has an increased concentration of calcium and phosphate, and (iii) has a higher mucous content than saliva of the parotid and sublingual glands. ${ }^{1,10}$ In addition, the submandibular duct is longer and the gland has an antigravity flow. ${ }^{1}$ Stone formation is not associated with systemic abnormalities of calcium metabolism. ${ }^{6}$ Electrolytes and parathyroid hormone studies in patients with sialolithiasis have not shown abnormalities. ${ }^{23}$ Gout is the only systemic illness known to predispose to salivary stone formation, ${ }^{23}$ although in gout the stones are made predominantly of uric acid. ${ }^{6}$ The proposed association between hard water areas and salivary calculi has been shown to be incorrect. ${ }^{24}$ The lack of association holds equally for both sexes. ${ }^{24}$ One study has suggested a link between sialolithiasis and nephrolithiasis, reporting an association in up to $10 \%$ of patients. 6,25

Sialolithiasis typically causes pain and swelling of the involved salivary gland by obstructing the food related surge of salivary secretion. Calculi may cause stasis of

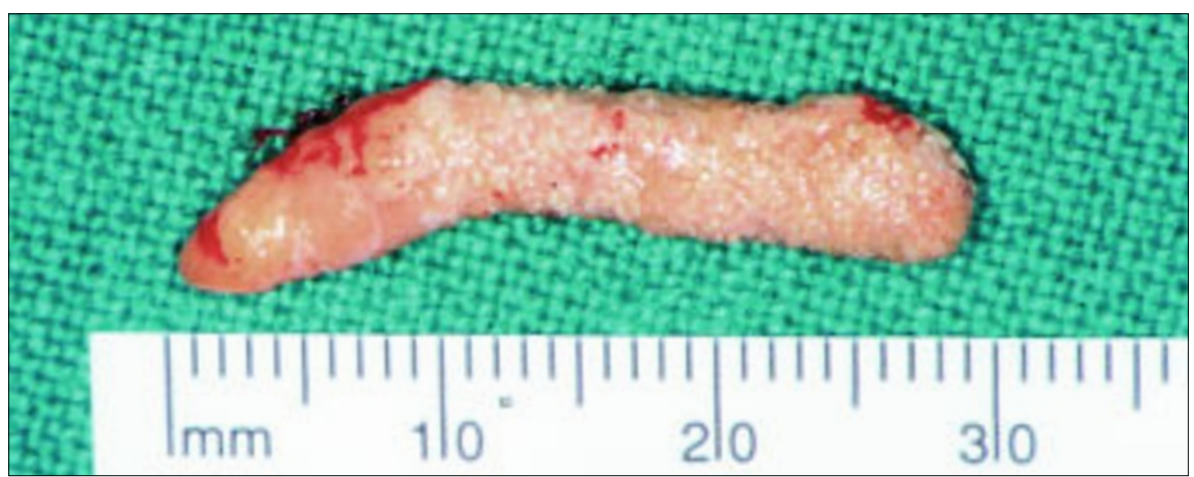

Figure 3 The calculus shown to scale saliva, leading to bacterial ascent into the parenchyma of the gland, ${ }^{6}$ and therefore infection, pain and swelling of the gland. Some may be asymptomatic until the stone passes forward and can be palpated in the duct or seen at the duct orifice. It may be possible that obstruction caused by large calculi is sometimes asymptomatic as obstruction is not complete and some saliva manages to seep through or around the calculus. ${ }^{1}$ Long term obstruction in the absence of infection can lead to atrophy of the gland with resultant lack of secretory function and ultimately fibrosis. ${ }^{6}$

\section{Diagnosis}

Careful history and examination are important in the diagnosis of sialolithiasis. Pain and swelling of the concerned gland at mealtimes and in response to other salivary stimuli are especially important. Complete obstruction causes constant pain and swelling, pus may be seen draining from the duct and signs of systemic infection may be present. $^{18}$

Bimanual palpation of the floor of the mouth, in a posterior to anterior direction, reveals a palpable stone in a large number of cases of submandibular calculi formation. Bimanual palpation of the gland itself can be useful, as a uniformly firm and hard gland suggests a hypo-functional or nonfunctional gland. ${ }^{6}$

For parotid stones, careful intraoral palpation around Stenson's duct orifice may reveal a stone. ${ }^{6}$ Deeper parotid stones are often not palpable.

When minor salivary glands are involved they are usually in the buccal mucosa or upper lip, forming a firm nodule that may mimic tumour. ${ }^{6,26}$

Imaging studies are very useful for diagnosing sialolithiasis. Occlusal radiographs are useful in showing radiopaque stones. It is very uncommon for patients to have a combination of radiopaque and radiolucent stones; ${ }^{27} 40 \%$ of parotid stones may be 
radiolucent. Sialography is thus useful in patients showing signs of sialadenitis related to radiolucent stones or deep submandibular/parotid stones. Sialography is, however, contraindicated in acute infection or in significant patient contrast allergy. ${ }^{6}$

\section{Treatment}

Patients presenting with sialolithiasis may benefit from a trial of conservative management, especially if the stone is small. ${ }^{6}$ The patient must be well hydrated and the clinician must apply moist warm heat and gland massage, while sialogogues are used to promote saliva production and flush the stone out of the duct. With gland swelling and sialolithiasis, infection should be assumed and a penicillinase resistant anti staphylococcal antibiotic prescribed. Most stones will respond to such a regimen, combined with simple sialolithotomy when required. ${ }^{18,19}$

Almost half of the submandibular calculi lie in the distal third of the duct and are amenable to simple surgical release through an incision in the floor of the mouth, which is relatively simple to perform and not usually associated with complications. ${ }^{28}$ If the stone is sufficiently forward it can be milked and manipulated through the duct orifice. This can be done with the aid of lacrimal probes and dilators to open the duct. Once open, the stone can be identified, milked forward, grasped and removed. The gland is then milked to remove any other debris in the more posterior portion of the duct. ${ }^{6}$

The duct may need opening to retrieve the stone. This involves a transoral approach where an incision is made directly onto the stone. In this way more posterior stones, 1-2 cm from the punctum, can be removed by cutting directly onto the stone in the longitudinal axis of the duct. Care is taken as the lingual nerve lies deep, but in close association with the submandibular duct posteriorly. Subsequently, the stone can be grasped and removed. No closure is done leaving the duct open for drainage.

If the gland has been damaged by recurrent infection and fibrosis, or calculi have formed within the gland, it may require removal.

Parotid stone management is more problematic as only a small segment of Stenson's duct is approachable through an intraoral incision. In addition, opening Stenson's duct can be complicated by subsequent stenosis of the duct whereas this is rare in the submandibular gland. As a result, parotidectomy is the mainstay of surgical management for the majority of intraglandular stones. This is reserved for patients whose symptoms do not respond to conservative therapy and suffer from recurrent pain and swelling.

Alternative methods of treatment have emerged such as the use of extracorporeal shock wave lithotripsy (ESWL) and more recently the use of endoscopic intracorporeal shockwave lithotripsy (EISWL), in which shockwaves are delivered directly to the surface of the stone lodged within the duct without damaging adjacent tissue (piezoelectric principle). ${ }^{29}$ Both extra and intracorporeal lithotripsy are gaining increasing importance in the treatment of salivary stone disease. ${ }^{4}$

In extracorporeal piezoelectric lithotripsy, the average size of fragments produced is about $0.7 \mathrm{~mm} .{ }^{22}$ Duct diameters are greater than $0.7 \mathrm{~mm}$ in general except for at the ostium. Therefore, fragments produced by ESWL would not be prohibited by duct diameters. Findings have also suggested that best results in salivary stone lithotripsy are achieved when the maximum size of stone fragments does not exceed $1.2 \mathrm{~mm} .^{22}$

Extracorporeal salivary lithotripsy provides another therapeutic option that carries fewer risks than surgical removal of the affected gland, such as the risks of a general anaesthetic, facial nerve damage, surgical scar, Frey's syndrome, and causes little discomfort to the patient whilst preserving the gland. ${ }^{29}$

A retrospective study of patients treated endoscopically from 1994 to 1999 showed a success rate of $83 \%$ with no severe complications. ${ }^{30}$ Endoscopy is a minimally invasive technique for removal of calculi from salivary glands as well as an excellent diagnostic procedure, ${ }^{31}$ as miniaturised endoscopes conforming to the physiological widths of the ducts are used to directly view and then deliver shock waves to the stones. $^{22}$

\section{CONCLUSION}

There are various methods available for the management of salivary stones, depending on the gland affected and stone location. These have been mentioned in the preceding paragraphs. It must be noted, however, that ESWL and EISWL offer alternatives to gland removal. Submandibular gland removal may be indicated following failure of lithotripsy or if the size of an intraglandular stone reaches $12 \mathrm{~mm}$ or more as the success of lithotripsy may be less than $20 \%$ in such cases. ${ }^{4}$ Parotid gland removal should only be carried out for cases of sialolithiasis resistant to minimally invasive techniques.

The author would like to thank Surgeon Commander D. K. Riden, Colonel R. M. Phillip and Surgeon Captain J. V. Holland, Consultants in Oral and Maxillofacial Surgery at the Royal Hospital Haslar, Gosport for their helpful advice in preparing this case report.

1. Leung A K, Choi M C, Wagner G A. Multiple sialolths and a sialolith of unusual size in the submandibular duct. Oral Surg, Oral Med, Oral Path, Oral Radiol, Endo 1999; 87: 331-333.

2. Cawson R A, Odell E W. Essentials of oral pathology and oral medicine. 6 th ed. pp 239-240. Edinburgh:
Churchill Livingstone, 1998.

3. Steiner M, Gould A R, Kushner G M, Weber R, Pesto A Sialolithiasis of the submandibular gland in an 8year-old child. OralSurg, Oral Med, Oral Pathol, Oral Radiol, Endod 1997; 83: 188.

4. Zenk J, Benzel W, Iro H. New modalities in the management of human sialolithiasis. Minimally invasive therapy 1994; 3: 275-284.

5. Tepan M G, Rohiwal R L. Multiple salivary calculi in Wharton's duct. J Laryngol Otol 1985; 99: 1313-1314.

6. Williams M F. Sialolithisis. Otolaryngologic Clinics of North America 1999; 32: 819-834.

7. Akin I, Esmer N. A submandibular sialolith of unusual size: a case report. J Otolaryngol 1991; 20: 123-125.

8. Hoggins GS. Large calcified mass in the submaxillary gland. Oral Surg, Oral Med, Oral Pathol 1968; 25: 679681.

9. Naraynsingh V. Giant submandibular gland calculi. J Oral Maxillofac Surg 1985; 43: 384-385.

10. Zakaria M A. Giant calculi of the submandibular salivary gland. Br J Oral Surg 1981; 19: 230-232.

11. Raskin SZ, Gould S M, Williams A C. Submandibular duct sialolith of unusual shape and size. J Oral Surg 1975: 33: 142-145.

12. Mustard TA. Calculus of unusual size in Wharton's duct. Br Dent J 1945; 79: 129.

13. Rust TA, Messerly $C D$. Oddities of salivary calculi. Oral Surg, Oral Med, Oral Pathol 1969; 28: 862-865.

14. Brusati R, Fiamminghi L. Large calculus of the submandibular gland: report of case. J Oral Surg 1973; 31: 710-711.

15. Carr S J. Sialolith of unusual size and configuration. Oral Surg, Oral Med, Oral Pathol 1965; 20: 709-712.

16. Marchul F. Kurt A M, Dulguerov P, Lehmann W. Retrograde Theory in sialolithiasis formation. Archives of Otolaryngology- Head and Neck Surgery 2001. $127: 66-8$

17. Rauch $S$, Gorlin R J. Disease of the salivary glands. In: Gorlin R J, Goldmann H M, eds. Thomas'Oral Pathology. St Loius, Mo: Mosby-Year Book Inc; 1970: 997-1003.

18. Pollack CV Jr, Severance H W Jr. Sialolithisis: case studies and review. J Emergency Medicine 1990. 8: 561-565.

19. Pietz D M, Bach D E. Submandibular sialolithisis. General Dentistry 1987; 35: 494-496.

20. Rice D H. Advances in diagnosis and management of salivary gland diseases. West J Med 1984; 140: 238249.

21. Blatt I. Studies in sialolithiasis: III. Pathogenesis, diagnosis, and treatment. South Med J 1964; 57: 723 728.

22. Zenk J, Werner G, Hosemann M D, Iro H. Diameters of the main excretory ducts of the adult human submandibular and parotid gland - a histological study. Oral Surg, Oral Med, Oral Pathol, Oral Radiol, Endod 1998; 85: 576-580.

23. Work W P, Hecht D W. Inflammatory diseases of the major salivary glands. In Papperalla M M, Shumrick D F (eds): Otolaryngology, vol 3, 1980. Philadelphia, W B Saunders, 2235-2243.

24. Sherman J A, McGurk M. Lack of correlation between water hardness and salivary calculi in England. $\mathrm{Br} J$ Oral Maxillofac Surg 2000; 38: 50-53

25. Lustmann J, RegevE, Melamed Y. Sialolithiasis: A survey on 245 patients and a review of the literature. Int J Oral Maxillofac Surg 1990; 19: 135-138.

26. Ho V, Currie W J R, Walker A. Sialolithisis of minor salivary glands. Br J Oral Maxillofac Surg 1992; 30: 273-275.

27. Isacsson G, Isberg A, Haverling M, et al. Salivary calculi and chronic sialadenitis of the submandibular gland: A radiographic and histological study. Oral Surg 1984 58: 622-627.

28. McGurk M, Esudier M. Removing salivary stones. Br J Hosp Med 1995; 54: 184-185.

29. Iro H, Schneider H Th, Fodra C et al. Shockwave lithotripsy of salivary duct stones. Lancet 1992; 339 1333-1336.

30. Nahlieli O, Baruchin A M. Long-term experience with endoscopic diagnosis and treatment of salivary gland inflammatory diseases. Laryngoscope 2000; 110: 988-993.

31. Nahlieli O, Baruchin A M. Sialendoscopy: three years experience as a diagnostic and treatment modality. J Oral Maxillofac Surg 1997; 55: 912-918. 